\title{
CHARLES TALIAFERRO
}

\section{ARE WE EMBODIED SOULS?}

I discovered Richard Swinburne's work in 1978 while under the scrutiny of a hyper-Kantian graduate school professor. Swinburne not only helped rescue my precarious, early years as a philosopher, he has been an inspiring resource for thinking about metaphysics, epistemology, space and time, philosophy of science, ethics, moral psychology, and philosophical theology. I am in fundamental agreement with the arguments in Are We Bodies or Souls? I will, however, try to be useful in proposing two areas where I believe the case for substance dualism might be strengthened.

\section{MIND OR SOUL AND BODY INTEGRATION}

I am a self-identified substance dualist. And yet it has been an almost lifetime project to argue that substance dualists should stress the goodness of our embodiment which, under healthy conditions, amounts to a functional unity. Under good conditions, to see and interact with my body is to see and interact with me. We still live under the specter of Gilbert Ryle, perpetuated by a multitude (Antony Flew, Anthony Kenney, Elizabeth Anscombe, John Wisdom, Daniel Dennett, Trenton Merriks, et al.) that caricatures dualism as positing a preposterous bifurcation, a ghost in a machine. Dualists are pictured as treating their bodies as containers or remote objects that they control like someone piloting a ship. Unfortunately, I suggest that some of Swinburne's language does not discourage this caricature.

Charles Taliaferro, Distinguished Professor of Philosophy at St. Olaf College; address for correspondence: Holland Hall 409, 1520 St. Olaf Avenue, Northfield, MN 55057, USA; e-mail: taliafer@stolaf.edu; ORCID: https://orcid.org/0000-0002-5729-0761. 
For what is it to have a body? It is to have a chunk of matter through which one can make a difference to the physical world (for example, by opening a door by grasping it with one's hand and pulling), and through which one learns about the world (for example, by light impinging on one's eyes and sound waves impinging on one's ears, and one's nerves transmitting signals from eyes and ears to the brain). (73-74) ${ }^{1}$

There is merit in this depiction. Swinburne's highlighting the cognitive side of embodiment has always been important. Interestingly, many skeptical arguments propose some breakdown of what appears to be our apparent embodiment (e.g., rather than appearing to be typing out this paper in my apartment, maybe I am currently a brain in a vat). But depicting our bodies as chunks of matter we can control and use to know about ourselves and the world does not come close to appreciating the functional unity of person and body. Your body is no mere chunk of matter; you actually function as an embodied being with all your senses (including proprioception), appetites, desires, motives, emotions, thinking, actions, and the like. The liabilities (being vulnerable to harm) and powers (all your capabilities/abilities) are all on display as an integrated, whole being. ${ }^{2}$

The above more integrated picture of soul or person and body remains a metaphysical case of substance dualism insofar as it maintains (as I do) that the person and body are not metaphysically identical, for example, I affirm that persons may persist after the annihilation of their bodies and their bodies may persist after persons have ceased to be. In the course of stressing the functional unity of person and body, I sometimes recommend the term 'integrative dualism' rather than 'substance dualism'. It should be recognized, however, that we can become so damaged that we are not at all integrated, but come to be in the world like a ghost in a machine. Early in his career, Bertrand Russell thought of himself as a ghost haunting his body. ${ }^{3}$

\section{THE PRIMACY OF THE FIRST PERSON}

One of the objections to Are we Souls or Bodies? is that Swinburne relies too heavily on the first-person point of view. In an otherwise positive review of the book, Thomas Nagel persistently raises the possibility that Swinburne may be right

\footnotetext{
${ }^{1}$ Richard Swinburne, Are We Bodies or Souls? (Oxford: OUP, 2019); page references are to this book.

${ }^{2}$ See my Consciousness and the Mind of God (Cambridge: CUP, 1994) and "The Virtues of Embodiment," Philosophy 76, no. 1 (2001): 111-25.

${ }^{3}$ See Ray Monk's biography of Bertrand Russell, The Spirit of Solitude 1872-1921 (New York: Free Press, 2016), chap. 1, "Ghosts."
} 
about our first-person point of view, but this might turn out to be illusory. Consider three passages from Nagel's review:

Admittedly the intuition that "I" is never indeterminate does not go away on reflection, but may it not be an illusion nonetheless - an illusion we are stuck with because no alternative is imaginable from the first-person point of view? ${ }^{4}$

The possibility that I might have a divided consciousness seems subjectively imaginable in a way that future indeterminacy does not. But even if I am wrong about this, there remains the question whether these subjective judgments are immune to revision on the basis of third-person physical and psychological observations.

There is a standoff here. Swinburne has shown that our first-person self-awareness appears to reveal a mental reality independent of anything physical; but we can take this appearance at face value only if we are confident that the mental has no metaphysically necessary connections with the physical that are concealed from the first-person point of view-which is precisely the issue. If Swinburne is right, we know who we are. If he is wrong, his arguments show that our natural sense of ourselves includes a large dose of stubborn illusion.

How might a substance dualist reply?

I recommend replying by arguing for the primacy of the first-person point of view. I have argued elsewhere that without relying on our awareness of ourselves as enduring, conscious thinking subjects we would lack any basis for our identifying enduring objects or events. ${ }^{5}$ To perceive persisting objects, I have to be self-aware of myself as a persisting subject. I would not be able to engage in typing or communicating or take up a third-person point of view without myself and others each having a first-person point of view. If we imagine what Nagel suggests, namely we discover that the first-person point of view is illusory, we would have just as much reason to think a third-person point of view is illusory.

My defense of the first-person point of view does not rest on the supposition that our first-person point of view cannot be revised or challenged from a third-person point of view. I might think of myself as humble and kind, whereas others have evidence that I am vain and cruel. But such corrections presuppose the reliability

${ }^{4}$ All citations of Nagel are from his review of Swinburne's book published online by the Notre Dame Philosophical Review, no. 2020.04.07, https://ndpr.nd.edu/news/are-we-bodies-or-souls.

${ }^{5}$ See my "Substance Dualism: A Defense," in The Blackwell Companion to Substance Dualism, ed. Jonathan J. Loose, Angus J. L. Menuge, and J. P. Moreland (Oxford: Wiley-Blackwell, 2018), 43-60. 
of our self-awareness as subjects; I might be corrected in the self-evaluation of my character, but this is not correcting my trusting that I am a persisting subject,

Swinburne writes about the physical world in a spirit of common sense. I cite him at some length.

So both properties such as having a certain mass or electric charge possessed by fundamental particles like electrons and protons, and properties possessed by larger inanimate substances composed of fundamental particles, such as being slippery or octagonal, or flat or mountainous, are physical properties. Thus a particular table is a physical substance, since the essential properties of such a table are being made of such-and-such solid matter (for example, wood or steel), having a flat surface, having a certain height, and being used by humans for putting things on. All of these properties are typical physical properties. Among other physical substances are gates, roads, trees, and other plants. (21-22)

From the position of common sense, this may be unobjectionable. But I suggest that what needs to be stressed is that without proper, persisting, first-person identity over time we would not be able to pick out gates, trees, and so on, or contemplate the account of our world in terms of contemporary physics. Risking repetition, I only know that a table persists over time if I have a more primordial (or logically antecedent) awareness of myself as a persisting subject.

So, Nagel raises this question: "Can we be sure that our first-person grasp of ourselves and who we are is sufficiently complete and accurate to allow us to determine with confidence the necessary and sufficient conditions of our existence, just by thinking?" To summarize my response, the first-person grasp of ourselves as complete persisting subjects is both necessary and sufficient for us to determine the persistence of any objects (including our bodies).

I end with a brief application of the position I have been developing in response to Nagel's defense of property dualism. Nagel cites Swinburne:

Since the two possible humans (Alexandra and the person who is not Alexandra) would have all the same properties, they could only be different from each other if one has a part which the other lacks. And, since they have all the same bodily, that is physical, parts, they must differ in the respect that one of them has a certain pure mental part which the other lacks, which I will call their 'soul' (70).

Nagel replies:

But it isn't clear that a theory of mere property dualism cannot make sense of the difference between these two possibilities. Even if the only substance involved is the body, which is the same in both cases, and the body has irreducibly mental properties 
which are qualitatively the same in both cases, why couldn't those mental states just have the further property of being Alexandra's in one case and not in the other? In the vein of first-person intuition that drives Swinburne's arguments, this seems imaginable without recourse to the presence or absence of a further, purely mental substance that underpins it.

I suggest that the problem with Nagel's reply is that Swinburne's thought experiment is about the substitution of one subject by another. A property is not a subject. The difference between Nagel and Swinburne is not that one has the property of being Nagel and the other instantiates the property of being Swinburne. The difference is between there being one self (a concrete, individual thing, not a property) and another one.

I have not challenged Swinburne's main arguments in his new, excellent book, as I find them cogent. I have, however, sought to strengthen Swinburne's position by proposing a more integrated form of dualism and developed a reply to one of Swinburne's critics by arguing for the primacy and integrity of the first-person point of view.

\section{BIBLIOGRAPHY}

Monk, Ray. The Spirit of Solitude 1872-1921. New York: Free Press, 2016.

Nagel, Thomas. Review of Are We Bodies or Souls? by Richard Swinburne. Notre Dame Philosophical Reviews, no. 2020.04.07. https://ndpr.nd.edu/news/are-we-bodies-or-souls.

Swinburne, Richard. Are We Bodies or Souls? Oxford: OUP, 2019.

Taliaferro, Charles. "Substance Dualism: A Defense." In The Blackwell Companion to Substance

Dualism, edited by Jonathan J. Loose, Angus J. L. Menuge, and J. P. Moreland (Oxford: WileyBlackwell, 2018), 43-60.

TAliaferro, Charles. "The Virtues of Embodiment." Philosophy 76, no. 1 (2001): 111-25.

TALiaferro, Charles. Consciousness and the Mind of God. Cambridge: CUP, 1994.

\section{ARE WE EMBODIED SOULS?}

\section{Sum mary}

It is argued that Swinburne should stress the functional unity of soul and body under most healthy conditions. Too often, critics of substance dualism charge dualists with promoting a problematic bifurcation between soul and body. Swinburne's work is defended against objections from Thomas Nagel. It is argued that Swinburne's appeal to the first-person point of view is sound.

Keywords: dualism; Thomas Nagel; first-person point of view. 